\title{
Detection of Lion Podoplanin Using the Antitiger Podoplanin Monoclonal Antibody PMab-231
}

\author{
Yukinari Kato,, ${ }^{1,2}$ Junko Takei, ${ }^{1}$ Masato Sano,, Teizo Asano,, Yusuke Sayama, \\ Kazuyuki Uchida, ${ }^{3}$ Takayuki Nakagawa, ${ }^{4}$ and Mika K. Kaneko ${ }^{1}$
}

Monoclonal antibodies (mAbs) that specifically target podoplanin (PDPN), a marker for type I alveolar cells, are needed for immunohistochemical analyses. Anti-PDPN mAbs are available for many species, including human, mouse, rat, rabbit, dog, cat, bovine, pig, Tasmanian devil, alpaca, tiger, whale, goat, horse, bear, and sheep PDPNs. However, no antilion PDPN (lioPDPN) antibody has been developed. In this study, possible cross-reaction between available anti-PDPN mAbs and lioPDPN was examined. Immunohistochemical analysis showed that antitiger PDPN mAb PMab-231 ( $\operatorname{IgG}_{2 \mathrm{a}}$, kappa) reacted with type I alveolar cells from lion lung, indicating that PMab-231 is useful for the detection of lioPDPN.

Keywords: lion podoplanin, PDPN, lioPDPN, PMab-231

\section{Introduction}

$\mathbf{P}$ ODOPLANIN (PDPN) IS A TYPE I TRANSMEMBRANE sialoglycoprotein that induces platelet aggregation through platelet C-type lectin-like receptor-2 (CLEC-2). ${ }^{(1)}$ It is composed of three platelet aggregation-stimulating (PLAG) domains, termed PLAG1-3 (EDxxVTPG sequence). ${ }^{(2)}$ Previously, PLAG3 is the most important domain for platelet aggregation by human PDPN. ${ }^{(2-4)}$ Recently, a PLAG-like domain (PLD; EDxxT sequence) was reported to be another critical sequence for PDPN-CLEC-2 interaction. ${ }^{(5)}$

Anti-PDPN monoclonal antibodies (mAbs) are useful in distinguishing lymphatic from vascular endothelial cells or type I from type II alveolar cells of the lung. ${ }^{(2,6)}$ PDPNs from many animals have been characterized using specific antiPDPN mAbs, including antimouse PDPN (PMab-1), ${ }^{(7)}$ antirat PDPN (PMab-2), ${ }^{(8)}$ antirabbit PDPN (PMab-32), ${ }^{(9)}$ antidog PDPN (PMab-38 ${ }^{(10)}$ and PMab-48, ${ }^{(11)}$ ) antibovine PDPN (PMab-44), ${ }^{(12)}$ anticat PDPN (PMab-52), ${ }^{(13)}$ antipig PDPN (PMab-213), ${ }^{(14)}$ anti-Tasmanian devil PDPN (PMab233), ${ }^{(15)}$ antialpaca PDPN (PMab-225), ${ }^{(16)}$ antitiger PDPN (PMab-231), ${ }^{(17)}$ antiwhale PDPN (PMab-237), ${ }^{(18)}$ antigoat PDPN (PMab-235), ${ }^{(19)}$ antihorse PDPN (PMab-219), ${ }^{(20)}$ antibear PDPN (PMab-247), ${ }^{(21)}$ and antisheep PDPN (PMab256). ${ }^{(22)}$ Furthermore, many antihuman PDPN mAbs have been developed, including NZ-1.2, ${ }^{(7)}$ LpMab-3, ${ }^{(23)}$ LpMab7, ${ }^{(23,24)}$ LpMab-9, ${ }^{(23)}$ LpMab-10, ${ }^{(25)}$ LpMab-12, ${ }^{(26)}$ LpMab$13,{ }^{(27)}$ LpMab-17, ${ }^{(28)}$ LpMab-19, ${ }^{(29)}$ and LpMab-21. ${ }^{(30,31)}$
LpMab-3, LpMab-9, LpMab-12, LpMab-19, and LpMab-21 are antiglycopeptide mAbs (GpMabs), epitopes of which include both peptides and glycans. Cancer-specific mAbs (CasMabs), such as LpMab-2 ${ }^{(23,32)}$ and LpMab-23, ${ }^{(33,34)}$ may be used for PDPN-targeted therapy ${ }^{(23,32-35)}$ since PDPN is expressed in many healthy tissues.

To date, antilion PDPN (lioPDPN) mAbs have not been reported. In the present study, cross-reaction between antiPDPN mAbs for various species and lioPDPN were examined using immunohistochemical analyses.

\section{Materials and Methods}

\section{Immunohistochemical analyses}

Lion lungs were collected at necropsy at the University of Tokyo, fixed in $10 \%$ neutral-buffered formalin, and processed routinely to produce formalin-fixed paraffinembedded tissue (FFPE) sections. Four micrometers histological sections were autoclaved in citrate buffer $(\mathrm{pH} 6.0$; Nichirei Biosciences, Inc., Tokyo, Japan) for 20 minutes. After blocking with SuperBlock T20 (PBS) Blocking Buffer (Thermo Fisher Scientific, Inc., Waltham, MA) for 15 minutes, sections were incubated with anti-PDPN mAbs $(10 \mu \mathrm{g} / \mathrm{mL})$ for 1 hour at room temperature and treated using Envision+ Kit (Agilent Technologies, Inc., Santa Clara, CA) for 30 minutes. Color was developed using 3,3-diaminobenzidine tetrahydrochloride (DAB; Agilent Technologies, Inc.) for 2 minutes, and finally, sections were counterstained

\footnotetext{
${ }^{1}$ Department of Antibody Drug Development, Tohoku University Graduate School of Medicine, Sendai, Japan.

${ }^{2}$ New Industry Creation Hatchery Center, Tohoku University, Sendai, Japan.

${ }^{3}$ Laboratory of Veterinary Pathology, Graduate School of Agricultural and Life Sciences, The University of Tokyo, Tokyo, Japan.

${ }^{4}$ Laboratory of Veterinary Surgery, Graduate School of Agricultural and Life Sciences, The University of Tokyo, Tokyo, Japan.
} 


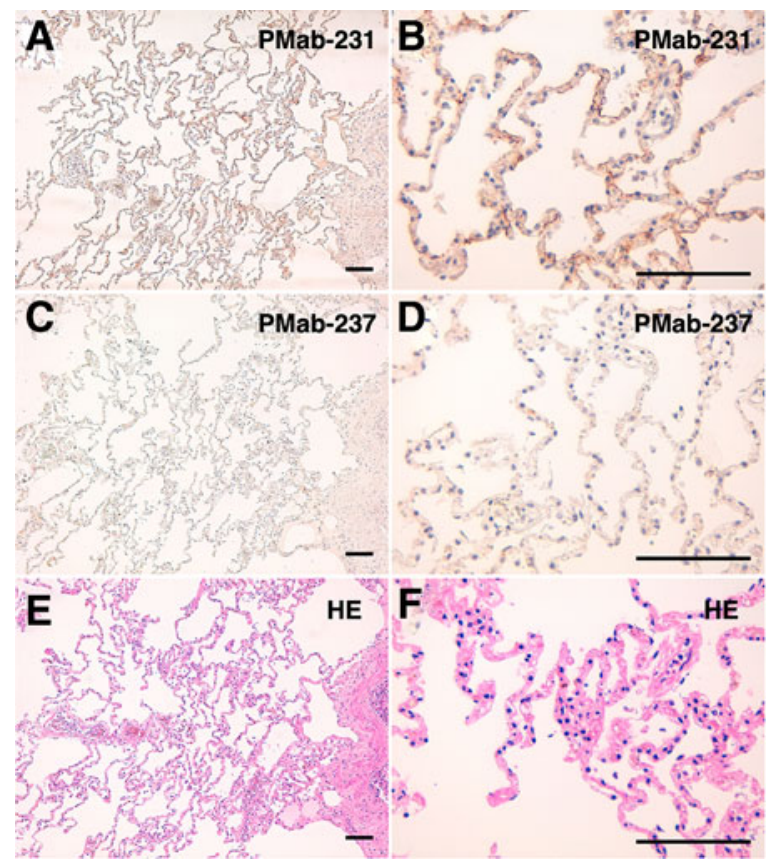

FIG. 1. Immunohistochemical analyses of lion lung tissues. Histological sections of the lion lung were directly autoclaved in citrate buffer for 20 minutes. After blocking, sections were incubated with $10 \mu \mathrm{g} / \mathrm{mL}$ of PMab-231 (A, B) or PMab-237 (C, D), followed by detection using Envision+ Kit. (E, F) HE staining. Scale bar $=100 \mu \mathrm{m}$. HE, hematoxylin and eosin.

with hematoxylin/eosin (FUJIFILM Wako Pure Chemical Corporation, Osaka, Japan).

\section{Results}

In this study, cross-reaction between anti-PDPN mAbs against several mammalian species and lioPDPN was examined because a specific anti-lioPDPN mAb has not been available. Immunohistochemical analysis revealed that antitiger PDPN mAb PMab-231 $\left(\operatorname{IgG}_{2 \mathrm{a}}\right.$, kappa) ${ }^{(17)}$ reacted with type I alveolar cells in lion lung (Fig. 1A, B). In contrast, PMab-237 (an antiwhale PDPN mAb) did not react with the lion lung using the next consecutive tissue section (Fig. 1C, D). Similarly, other anti-PDPN mAbs, including all mAbs already listed did not react with the lion lung using additional consecutive tissue sections (data not shown). Hematoxylin and eosin staining using the final consecutive tissue section indicated that tissue was well preserved (Fig. 1C).

Using the same methods, PMab-231 staining of other tissues was investigated, since PDPN is expressed in tissues other than lung. ${ }^{(6,36)}$ PMab-231 did not stain renal podocytes, Bowman's capsule, or lymphatic endothelial cells (data not shown).

\section{Discussion}

To date, antilioPDPN mAbs have not been established due to lack of the relevant amino acid or DNA sequence of lioPDPN using fresh lion lung tissues. Instead, anti-PDPN mAbs developed for several mammalian tissues were tested for cross-reaction with lion lung, collected at necropsy, using immunohistochemical analyses. Only antitiger PDPN mAb
(PMab-231) stained type I alveolar cells of lion lung (Fig. 1). Previously, PMab-231 specifically detected tiger PDPN using flow cytometry, Western blot, and immunohistochemical analyses. ${ }^{(17)}$ PMab-231 cross-reacted with cat PDPN, and stained type I alveolar cells using immunohistochemistry. Dissociation constants $\left(K_{\mathrm{D}}\right)$ of PMab-231 for PDPNexpressing $\mathrm{CHO}-\mathrm{K} 1$ cells $(\mathrm{CHO} /$ tigPDPN and cPDPN) were determined to be $1.2 \times 10^{-8}$ and $1.9 \times 10^{-8}$, for tiger and cat, respectively, indicating similar affinity across species.

Although the staining intensity of PMab-231 against lion lung seems weak (Fig. 1), intensity of PMab-231 in cat lung was previously moderate to strong. ${ }^{(17)}$ This difference is likely due to variation in binding epitopes between cat and lion, or PDPN protein in FFPE sections of lion tissues might have been damaged. Lack of reaction of PMab-231 with kidney and colon tissues remains unexplained. Similar data were observed previously using an antibovine PDPN mAb (PMab-44) against sheep, ${ }^{(37)}$ goat, ${ }^{(38)}$ and alpaca tissues. ${ }^{(39)}$ Thus, expression levels of PDPN in the lung may be higher than levels in kidney or colon, or, perhaps binding epitopes of mAbs are different among tissues due to post-translational modification, such as glycosylation. Additional lion tissues could be investigated to further characterize immunoreactivity of PMab-231.

\section{Author Disclosure Statement}

No competing financial interests exist.

\section{Funding Information}

This research was supported, in part, by AMED under Grant Nos. JP20am0401013 (Y.K.), JP20am0101078 (Y.K.), and JP20ae0101028 (Y.K.), and by JSPS KAKENHI Grant No. 17K07299 (M.K.K.) and Grant No. 19K07705 (Y.K.).

\section{References}

1. Kato Y, Kaneko MK, Kunita A, Ito H, Kameyama A, Ogasawara S, Matsuura N, Hasegawa Y, Suzuki-Inoue K, Inoue O, Ozaki Y, and Narimatsu H: Molecular analysis of the pathophysiological binding of the platelet aggregationinducing factor podoplanin to the C-type lectin-like receptor CLEC-2. Cancer Sci 2008;99:54-61.

2. Kato Y, Fujita N, Kunita A, Sato S, Kaneko M, Osawa M, and Tsuruo T: Molecular identification of Aggrus/T1alpha as a platelet aggregation-inducing factor expressed in colorectal tumors. J Biol Chem 2003;278:51599-51605.

3. Kaneko M, Kato Y, Kunita A, Fujita N, Tsuruo T, and Osawa M: Functional sialylated O-glycan to platelet aggregation on Aggrus (T1alpha/podoplanin) molecules expressed in Chinese Hamster Ovary cells. J Biol Chem 2004; 279:38838-38843.

4. Kaneko MK, Kato Y, Kitano T, and Osawa M: Conservation of a platelet activating domain of Aggrus/podoplanin as a platelet aggregation-inducing factor. Gene 2006;378: 52-57.

5. Kato Y, Takei J, Furusawa Y, Sayama Y, Sano M, Konnai S, Kobayashi A, Harada H, Takahashi M, Suzuki H, Yamada S, and Kaneko MK: Epitope mapping of anti-bear podoplanin monoclonal antibody PMab-247. Monoclon Antib Immunodiagn Immunother 2019;38:230-233.

6. Breiteneder-Geleff S, Soleiman A, Kowalski H, Horvat R, Amann G, Kriehuber E, Diem K, Weninger W, Tschachler 
E, Alitalo K, and Kerjaschki D: Angiosarcomas express mixed endothelial phenotypes of blood and lymphatic capillaries: Podoplanin as a specific marker for lymphatic endothelium. Am J Pathol 1999;154:385-394.

7. Kaji C, Tsujimoto Y, Kato Kaneko M, Kato Y, and Sawa Y: Immunohistochemical examination of novel rat monoclonal antibodies against mouse and human podoplanin. Acta Histochem Cytochem 2012;45:227-237.

8. Oki H, Honma R, Ogasawara S, Fujii Y, Liu X, Takagi M, Kaneko MK, and Kato Y: Development of sensitive monoclonal antibody PMab-2 against rat podoplanin. Monoclon Antib Immunodiagn Immunother 2015;34:396-403.

9. Honma R, Fujii Y, Ogasawara S, Oki H, Liu X, Nakamura T, Kaneko MK, Takagi M, and Kato Y: Establishment of a novel monoclonal antibody PMab-32 against rabbit podoplanin. Monoclon Antib Immunodiagn Immunother 2016; 35:41-47.

10. Honma R, Kaneko MK, Ogasawara S, Fujii Y, Konnai S, Takagi M, and Kato Y: Specific detection of dog podoplanin expressed in renal glomerulus by a novel monoclonal antibody PMab-38 in immunohistochemistry. Monoclon Antib Immunodiagn Immunother 2016;35: 212-216.

11. Yamada S, Itai S, Kaneko MK, and Kato Y: PMab-48 recognizes dog podoplanin of lymphatic endothelial cells. Monoclon Antib Immunodiagn Immunother 2018;37:63-66.

12. Honma R, Ogasawara S, Kaneko M, Fujii Y, Oki H, Nakamura T, Takagi M, Konnai S, and Kato Y: PMab-44 detects bovine podoplanin in immunohistochemistry. Monoclon Antib Immunodiagn Immunother 2016;35: 186-190.

13. Nakano T, Ogasawara S, Tanaka T, Hozumi Y, Mizuno S, Satoh E, Sakane F, Okada N, Taketomi A, Honma R, Nakamura T, Saidoh N, Yanaka M, Itai S, Handa S, Chang YW, Yamada S, Kaneko MK, Kato Y, and Goto K: DaMab-2: Anti-human DGKalpha monoclonal antibody for immunocytochemistry. Monoclon Antib Immunodiagn Immunother 2017;36:181-184.

14. Kato Y, Yamada S, Furusawa Y, Itai S, Nakamura T, Yanaka M, Sano M, Harada H, Fukui M, and Kaneko MK: PMab-213: A monoclonal antibody for immunohistochemical analysis against pig podoplanin. Monoclon Antib Immunodiagn Immunother 2019;38:18-24.

15. Furusawa Y, Yamada S, Itai S, Nakamura T, Takei J, Sano M, Harada H, Fukui M, Kaneko MK, and Kato Y: Establishment of a monoclonal antibody PMab-233 for immunohistochemical analysis against Tasmanian devil podoplanin. Biochem Biophys Rep 2019;18:100631.

16. Kato Y, Furusawa Y, Yamada S, Itai S, Takei J, Sano M, and Kaneko MK: Establishment of a monoclonal antibody PMab-225 against alpaca podoplanin for immunohistochemical analyses. Biochem Biophys Rep 2019;18:100633.

17. Furusawa Y, Kaneko MK, Nakamura T, Itai S, Fukui M, Harada H, Yamada S, and Kato Y: Establishment of a monoclonal antibody PMab-231 for tiger podoplanin. Monoclon Antib Immunodiagn Immunother 2019;38: 89-95.

18. Kato Y, Furusawa Y, Itai S, Takei J, Nakamura T, Sano M, Harada H, Yamada S, and Kaneko MK: Establishment of an anticetacean podoplanin monoclonal antibody PMab237 for immunohistochemical analysis. Monoclon Antib Immunodiagn Immunother 2019;38:108-113.

19. Furusawa Y, Yamada S, Nakamura T, Sano M, Sayama Y, Itai S, Takei J, Harada H, Fukui M, Kaneko MK, and Kato
Y: PMab-235: A monoclonal antibody for immunohistochemical analysis against goat podoplanin. Heliyon 2019;5: e02063.

20. Furusawa Y, Yamada S, Itai S, Nakamura T, Yanaka M, Sano M, Harada H, Fukui M, Kaneko MK, and Kato Y: PMab-219: A monoclonal antibody for the immunohistochemical analysis of horse podoplanin. Biochem Biophys Rep 2019;18:100616.

21. Furusawa Y, Takei J, Sayama Y, Yamada S, Kaneko MK, and Kato Y: Development of an anti-bear podoplanin monoclonal antibody PMab-247 for immunohistochemical analysis. Biochem Biophys Rep 2019;18:100644.

22. Kato Y, Furusawa Y, Sano M, Takei J, Nakamura T, Yanaka M, Okamoto S, Handa S, Komatsu Y, Asano T, Sayama Y, and Kaneko MK: Development of an antisheep podoplanin monoclonal antibody PMab-256 for immunohistochemical analysis of lymphatic endothelial cells. Monoclon Antib Immunodiagn Immunother 2020; 39:82-90.

23. Kato Y, and Kaneko MK: A cancer-specific monoclonal antibody recognizes the aberrantly glycosylated podoplanin. Sci Rep 2014;4:5924.

24. Kato Y, Kunita A, Abe S, Ogasawara S, Fujii Y, Oki H, Fukayama M, Nishioka Y, and Kaneko MK: The chimeric antibody chLpMab-7 targeting human podoplanin suppresses pulmonary metastasis via $\mathrm{ADCC}$ and $\mathrm{CDC}$ rather than via its neutralizing activity. Oncotarget 2015;6:3600336018.

25. Ogasawara S, Oki H, Kaneko MK, Hozumi Y, Liu X, Honma R, Fujii Y, Nakamura T, Goto K, Takagi M, and Kato Y: Development of monoclonal antibody LpMab-10 recognizing non-glycosylated PLAG1/2 domain including Thr34 of human podoplanin. Monoclon Antib Immunodiagn Immunother 2015;34:318-326.

26. Kato Y, Ogasawara S, Oki H, Goichberg P, Honma R, Fujii Y, and Kaneko MK: LpMab-12 Established by CasMab technology specifically detects sialylated O-glycan on Thr52 of platelet aggregation-stimulating domain of human podoplanin. PLoS One 2016;11:e0152912.

27. Ogasawara S, Kaneko MK, Honma R, Oki H, Fujii Y, Takagi M, Suzuki H, and Kato Y: Establishment of mouse monoclonal antibody LpMab-13 against human podoplanin. Monoclon Antib Immunodiagn Immunother 2016;35: $155-162$.

28. Kato Y, Ogasawara S, Oki H, Honma R, Takagi M, Fujii Y, Nakamura T, Saidoh N, Kanno H, Umetsu M, Kamata S, Kubo H, Yamada M, Sawa Y, Morita K, Harada H, Suzuki H, and Kaneko MK: Novel monoclonal antibody LpMab17 developed by CasMab technology distinguishes human podoplanin from monkey podoplanin. Monoclon Antib Immunodiagn Immunother 2016;35:109-116.

29. Ogasawara S, Kaneko MK, and Kato Y: LpMab-19 recognizes sialylated O-glycan on Thr76 of human podoplanin. Monoclon Antib Immunodiagn Immunother 2016;35: 245-253.

30. Kaneko MK, Nakamura T, Honma R, Ogasawara S, Fujii Y, Abe S, Takagi M, Harada H, Suzuki H, Nishioka Y, and Kato Y: Development and characterization of antiglycopeptide monoclonal antibodies against human podoplanin, using glycan-deficient cell lines generated by CRISPR/Cas9 and TALEN. Cancer Med 2017;6:382396.

31. Kato Y, Kunita A, Fukayama M, Abe S, Nishioka Y, Uchida H, Tahara H, Yamada S, Yanaka M, Nakamura T, 
Saidoh N, Yoshida K, Fujii Y, Honma R, Takagi M, Ogasawara S, Murata T, and Kaneko MK: Antiglycopeptide mouse monoclonal antibody LpMab-21 exerts antitumor activity against human podoplanin through antibodydependent cellular cytotoxicity and complement-dependent cytotoxicity. Monoclon Antib Immunodiagn Immunother 2017;36:20-24.

32. Kaneko MK, Yamada S, Nakamura T, Abe S, Nishioka Y, Kunita A, Fukayama M, Fujii Y, Ogasawara S, and Kato Y: Antitumor activity of chLpMab-2, a human-mouse chimeric cancer-specific antihuman podoplanin antibody, via antibody-dependent cellular cytotoxicity. Cancer Med 2017;6:768-777.

33. Yamada S, Kaneko MK, and Kato Y: LpMab-23: A cancerspecific monoclonal antibody against human podoplanin. Monoclon. Antib Immunodiagn Immunother 2017;36: 72-76.

34. Kaneko MK, Nakamura T, Kunita A, Fukayama M, Abe S, Nishioka Y, Yamada S, Yanaka M, Saidoh N, Yoshida K, Fujii Y, Ogasawara S, and Kato Y: ChLpMab-23: Cancerspecific human-mouse chimeric anti-podoplanin antibody exhibits antitumor activity via antibody-dependent cellular cytotoxicity. Monoclon Antib Immunodiagn Immunother 2017;36:104-112.

35. Miyazaki A, Nakai H, Sonoda T, Hirohashi Y, Kaneko MK, Kato Y, Sawa Y, and Hiratsuka H: LpMab-23-recognizing cancer-type podoplanin is a novel predictor for a poor prognosis of early stage tongue cancer. Oncotarget 2018;9: 21156-21165.

36. Breiteneder-Geleff S, Matsui K, Soleiman A, Meraner P, Poczewski H, Kalt R, Schaffner G, and Kerjaschki D: Podoplanin, novel 43-kd membrane protein of glomerular epithelial cells, is down-regulated in puromycin nephrosis. Am J Pathol 1997;151:1141-1152.

37. Kato Y, Yamada S, Itai S, Kobayashi A, Konnai S, and Kaneko MK: Immunohistochemical detection of sheep podoplanin using an antibovine podoplanin monoclonal antibody PMab-44. Monoclon Antib Immunodiagn Immunother 2018;37:265-268.

38. Yamada S, Kaneko MK, Furusawa Y, Itai S, Sano M, Nakamura T, Yanaka M, Handa S, Hisamatsu K, Nakamura Y, Koyanagi M, Fukui M, Harada H, and Kato Y: Antibovine podoplanin monoclonal antibody PMab-44 detects goat podoplanin in immunohistochemistry. Monoclon Antib Immunodiagn Immunother 2019;38:96-99.

39. Kato Y, Yamada S, Itai S, Konnai S, Kobayashi A, and Kaneko MK: Detection of alpaca podoplanin by immunohistochemistry using the anti-bovine podoplanin monoclonal antibody PMab-44. Monoclon Antib Immunodiagn Immunother 2018;37:269-271.

Address correspondence to: Yukinari Kato New Industry Creation Hatchery Center Tohoku University 2-1 Seiryo-machi Aoba-ku Sendai 980-8575 Japan

E-mail: yukinarikato@med.tohoku.ac.jp

Received: March 9, 2020 Accepted: April 15, 2020 